BMJ Open

Diabetes

Research

\& Care

\title{
Clinical correlates of plasma insulin levels over the life course and association with incident type 2 diabetes: the Framingham Heart Study
}

\author{
Wolfgang Lieb (D) , , ${ }^{1,2}$ Camila Maciel de Oliveira (D) , ${ }^{1}$ Stephanie Pan, ${ }^{3,4}$ \\ Justin Basile Echouffo-Tcheugui (1) , ${ }^{5}$ Katharina Susanne Weber, ${ }^{2}$ \\ Ramachandran S Vasan (D) , 1,3,6,7 Vanessa Xanthakis (1) 1,3,4
}

To cite: Lieb W, de Oliveira CM, Pan S, et al. Clinical correlates of plasma insulin levels over the life course and association with incident type 2 diabetes: the Framingham Heart Study. BMJ Open Diab Res Care 2022;10:e002581. doi:10.1136/ bmjdrc-2021-002581

- Additional supplemental material is published online only. To view, please visit the journal online (http://dx.doi. org/10.1136/bmjdrc-2021002581).

Received 5 September 2021 Accepted 15 January 2022

Check for updates

\section{(C) Author(s) (or their} employer(s)) 2022. Re-use permitted under CC BY-NC. No commercial re-use. See rights and permissions. Published by BMJ.

For numbered affiliations see end of article.

Correspondence to Dr Wolfgang Lieb; wolfgang.lieb@epi.uni-kiel.de and Dr Vanessa Xanthakis; vanessax@bu.edu

\section{ABSTRACT}

Introduction Insulin is a glucose-lowering hormone that affects carbohydrate, lipid, and protein metabolism. Limited data exist on the correlates of insulin levels over the life course in healthy community-dwelling individuals. Research design and methods Using multilevel modeling of multiple serial observations over 21 years, we assessed the longitudinal correlates of fasting insulin and the cross-sectional correlates of fasting and 2-hour $(2 \mathrm{~h}$, post $75 \mathrm{~g}$ glucose challenge) plasma insulin concentrations in 2140 relatively healthy Framingham Heart Study participants without diabetes (61\% women; mean age, 42 years). We used multivariable-adjusted Cox regression to relate glycemic markers (fasting and $2 \mathrm{~h}$-insulin, fasting glucose, 2h-glucose, and hemoglobin $A_{1 C}$ ) to the risk of type 2 diabetes during follow-up.

Results Over the life course, fasting insulin concentrations were inversely associated with age, male sex, and physical activity, whereas waist circumference, the total/ high-density lipoprotein (HDL) cholesterol ratio, and blood triglycerides were positively associated with insulin levels $(p<0.005$ for all). Male sex (inversely related) and the total/ HDL cholesterol ratio (positively related) emerged as the most important cross-sectional correlates of $2 \mathrm{~h}$-insulin $(p<0.005$ for all). All markers were associated with higher risk of type 2 diabetes (352 cases, median follow-up 18 years, $p<0.001$ for all).

Conclusions We observed common and distinct correlates of fasting and $2 \mathrm{~h}$-insulin levels. Our findings highlight a potential role of insulin in lipid and lipoprotein metabolism. Furthermore, fasting and $2 \mathrm{~h}$-insulin are critical markers of future diabetes risk. Further studies are needed to confirm our findings.

\section{INTRODUCTION}

Insulin is a proteo-hormone affecting carbohydrate, lipid, and protein metabolism. ${ }^{1}$ One of its primary functions is to lower blood glucose levels by stimulating the uptake and storage of glucose in adipocytes and peripheral muscles. ${ }^{2}$ As a critical anabolic hormone,

\section{Significance of this study}

What is already known about this subject?

> Insulin production and secretion are regulated by various factors, with blood glucose levels having a strong impact. Prior analyses identified crosssectional associations of fasting insulin concentrations; for example, with obesity, lipids, and physical activity.

- Mounting evidence exists that the metabolic determinants of fasting and 2-hour (2h) postload plasma glucose and insulin may be different.

What are the new findings?

- We observed that lipid traits and sex were significantly associated with both, fasting and $2 \mathrm{~h}$ insulin levels.

- Age, physical activity and waist circumference were Iongitudinal correlates of fasting plasma insulin, but not of $2 \mathrm{~h}$ insulin after adjusting for $2 \mathrm{~h}$ glucose.

- During a median follow-up of 18 years, fasting and $2 \mathrm{~h}$ insulin levels displayed strong associations with incident type 2 diabetes.

How might these results change the focus of research or clinical practice?

- Our results underscore the relevance of insulin levels not only for glucose homeostasis but also for lipid and lipoprotein metabolism. This might impact the clinical management of individuals with insulin resistance, the metabolic syndrome and diabetes.

insulin also promotes cell growth. ${ }^{1}$ Impaired insulin production or secretion and a reduced response to the physiological actions of insulin (insulin resistance) are important pathomechanisms underlying the presence of type 2 diabetes mellitus. We are observing an increasing trend in the incidence of type 2 diabetes in the USA and worldwide. ${ }^{3}$

Insulin resistance and the associated elevated circulating insulin levels (hyperinsulinemia) confer higher risks of type 2 
diabetes ${ }^{4}$ and for cardiovascular disease (CVD) events, ${ }^{5}$ but the underlying mechanisms remain unclear. Understanding physiological, clinical and biochemical correlates influencing interindividual variation in insulin concentrations over the life course is important in order to elucidate factors that may contribute to hyperinsulinemia. Insulin production and secretion are regulated by different dietary components and hormones, with glucose levels having a strong impact. ${ }^{6}$ Prior studies have assessed clinical and biochemical correlates of fasting insulin concentrations in the community, but most used a cross-sectional design. ${ }^{7-9}$ Data on the longitudinal assessment of insulin over the life course in individuals free of diabetes are scant. ${ }^{10-13}$ Furthermore, the correlates of 2-hour (2h) postload (postprandial) insulin levels have less commonly been investigated in community-based settings. ${ }^{9}$ Of note, there is mounting evidence that the metabolic determinants of impaired fasting glucose and impaired glucose tolerance (characterized by normal fasting glucose, but elevated 2h-postload glucose) are different. ${ }^{14}$ However, studies focusing on the metabolic differences between fasting versus $2 \mathrm{~h}$-insulin are relatively scarce. $^{9}$

In the present investigation, we examined the crosssectional and longitudinal correlates of fasting plasma insulin concentrations using data from participants of two generations of the community-based Framingham Heart Study (FHS). Additionally, we evaluated the crosssectional correlates of insulin concentrations obtained 2 hours after a $75 \mathrm{~g}$ oral glucose challenge. Given the availability of repeated measurements of insulin over time and the deep phenotyping of our samples, they can offer important information regarding a range of factors that may influence circulating insulin levels. Lastly, we assessed the associations of fasting insulin levels, 2h-insulin concentrations, and standard glycemic markers (fasting glucose, 2h-glucose, hemoglobin $\mathrm{A}_{1 \mathrm{C}}\left(\mathrm{HbA}_{1 \mathrm{C}}\right)$ ) with the risk of developing new-onset type 2 diabetes during a follow-up period of approximately 20 years.

We hypothesized that insulin levels will vary with age, differ between men and women, and will be associated with different cardiometabolic risk factors over the life course. Furthermore, we hypothesized that higher fasting and 2h-insulin levels will be associated with an increased risk of type 2 diabetes.

\section{RESEARCH DESIGN AND METHODS}

\section{Study sample}

The eligibility criteria, recruitment and design of the FHS have been described previously. ${ }^{15}$ Our base sample consisted of 8230 FHS participants from the Offspring cohort $(\mathrm{n}=4135)$ and the Third Generation (Gen 3; $\mathrm{n}=4095$ ) (online supplemental figure 1). Participants were eligible for the present investigation if they had attended at least one of examination cycles 5 (19911995), 7 (1998-2001), 8 (2005-2008) or 9 (2011-2014) of the Offspring cohort, or at least one of examination cycles 1 (2002-2005) or 2 (2008-2011) of the Gen 3 cohort. From the base sample, we excluded individuals with prevalent type 2 diabetes $(n=483)$, prevalent CVD $(n=465)$, and those with missing insulin values $(n=10)$, resulting in an overall sample of $\mathrm{n}=7272$ (online supplemental figure 1). We defined the following subsamples for analyses:

- To assess the longitudinal correlates of fasting plasma insulin, we created a healthy sample from the overall sample by excluding individuals with dyslipidemia $(n=2502)$, hypertension $(n=1458)$, abdominal obesity $(n=750)$, and smoking $(n=422)$, resulting in a sample size of 2140 individuals, who contributed 3116 personobservations (sample 1). More specifically, our analyses included 718 individuals with two observations (insulin measurements), 69 individuals with three observations and 40 individuals with more than three observations. The average time from the initial exam to the follow-up exam was 3 years. For participants with multiple follow-up exams, the average follow-up time was 8 years.

- To assess the cross-sectional correlates of fasting plasma insulin and of $2 \mathrm{~h}$-insulin, respectively, we used data from individuals of the healthy sample 1 who attended examination cycle 5 of the Offspring cohort $(n=565$, sample 2) because 2h-insulin levels were only available at that examination cycle. We used this same sample (sample 2) to assess the cross-sectional correlates of fasting plasma insulin to facilitate a comparison with the correlates of 2h-plasma insulin levels.

- Finally, to evaluate the associations of different glycemic markers, that is, fasting plasma insulin, 2h-insulin, fasting plasma glucose, 2h-glucose, and $\mathrm{HbA}_{1 \mathrm{C}}$, with the incidence of type 2 diabetes on follow-up, we created a third sample as follows: from the overall sample $(\mathrm{n}=7272)$, we included only those participants who attended examination cycle 5 because 2 h-insulin and 2h-glucose were only available at Offspring exam 5 ( $\mathrm{n}=3078$, sample 3).

All participants provided written informed consent. The corresponding authors had full access to all results and take responsibility for their integrity.

\section{Assessment of insulin, glucose, and $\mathrm{HbA}_{1 \mathrm{C}}$}

Participants had blood drawn after an overnight fast. At examination cycle 5 of the Offspring cohort, participants additionally underwent a $75 \mathrm{~g}$ oral glucose challenge. They had blood drawn for the assessment of glucose and insulin 2 hours after the glucose challenge. A detailed list of the assays used to measure insulin, glucose and $\mathrm{HbA}_{1 \mathrm{C}}$ at the different examination cycles in the Offspring and Gen 3 cohorts is provided in online supplemental table 1 . Given the varying methods for insulin assessment across examination cycles within each cohort, insulin values were standardized (mean $=0 ; \mathrm{SD}=1$ ) within each examination cycle for both cohorts.

$\mathrm{HbA}_{1 \mathrm{C}}$ was measured by high-performance liquid chromatography assays standardized to Diabetes Control and 
Complication Trial values ${ }^{16}$ with intra-assay and interassay coefficients of variation (CVs) lower than $3 \%$.

\section{Assessment of covariates}

At each FHS examination, standardized interviews were conducted by trained personnel obtaining information on sociodemographic characteristics and lifestyle factors and on medical history and medications used by the participants. Height (in meters) and weight (in kilograms) were measured, and body mass index (BMI) was calculated $\left(\mathrm{kg} / \mathrm{m}^{2}\right)$. Blood pressure (BP) was measured twice on the left arm of the seated participants with a mercury column sphygmomanometer and a cuff of an appropriate size; the average of the two readings was used as the BP at that examination cycle. Blood $\mathrm{C}$ reactive protein (CRP), total cholesterol, and high-density lipoprotein (HDL) cholesterol concentrations were obtained by standard enzymatic methods. Physical activity was assessed using a standardized questionnaire; for this investigation, we used the Physical Activity Index ${ }^{17}$ which is a weighted score that takes into account the time during a typical day spent sleeping, sedentarily, or in light, moderate or heavy activity. ${ }^{17}$

\section{Outcome of interest}

FHS participants are under regular surveillance for the incidence of outcomes, including type 2 diabetes. For this study, the incidence of type 2 diabetes was assessed from Offspring examination cycle 5 (1991-1995) through Offspring examination cycle 9 (2011-2014). Type 2 diabetes was defined as fasting plasma glucose level $\geq 126 \mathrm{mg} / \mathrm{dL}$ or the self-reported use of hypoglycemic medications. ${ }^{18}$

\section{Statistical analyses}

\section{Longitudinal tracking of fasting plasma insulin}

In our primary analyses, fasting plasma insulin was logtransformed to normalize its distribution and then standardized within each exam to account for the different assays used to measure insulin levels. We used multilevel modeling in sample 1 (SAS Proc Mixed) with an unstructured covariance matrix to assess the longitudinal correlates of fasting plasma insulin levels (dependent variable). Random intercept and slope for age were examined for all models to reflect the different starting values and slopes for insulin in each participant. We also investigated possible non-linear relations between age and insulin by examining the quadratic effect of age (by fitting an agesquared term). Models included the following eligible correlates: age, sex, waist circumference, systolic BP, the total/HDL cholesterol ratio, triglycerides, CRP, and the Physical Activity Index. We chose waist circumference over BMI, because the former better reflects cardiometabolic risk, including the risk of developing diabetes, than BMI. ${ }^{19}$ We also included fasting plasma glucose or $\mathrm{HbA}_{1 \mathrm{C}}$ among the candidate correlates (separate model for each) in order to account for glycemic status. We evaluated possible non-linear relations between fasting plasma glucose and 2h-glucose in relation to insulin by including a squared term for the respective covariate in the models. Additionally, we assessed biologically plausible interactions of sex with fasting plasma insulin, fasting plasma glucose, and $\mathrm{HbA}_{1 \mathrm{C}}$ by including corresponding interaction terms in the models. As a secondary analysis, we reran our longitudinal correlates analysis without standardizing the log-transformed fasting plasma insulin and instead included 'assay method' as a random effect in the multilevel mixed model to account for any unobserved confounding between assay methods.

Cross-sectional correlates of fasting plasma insulin and $2 \mathrm{~h}$-insulin Given that 2h-insulin was measured only at Offspring examination cycle 5, we used a multivariable-adjusted linear regression model (in sample 2) to assess the crosssectional correlates of $2 \mathrm{~h}$-insulin and of fasting plasma insulin (dependent variables; separate model for each). Candidate correlates were age, sex, waist circumference, systolic BP, the total/HDL cholesterol ratio, triglycerides, Physical Activity Index, and fasting plasma insulin (for the 2h-insulin models only). We also included fasting plasma glucose or $\mathrm{HbA}_{1 \mathrm{C}}$ among the candidate correlates (separate model for each) to account for glycemic status.

Associations of insulin and glycemic markers with incident type 2 diabetes

We generated cumulative probability curves using the Kaplan-Meier method to display the unadjusted associations of fasting plasma insulin, $2 \mathrm{~h}$-insulin, fasting plasma glucose, 2h-glucose, and $\mathrm{HbA}_{1 \mathrm{C}}$ (separate curve for each marker, each marker dichotomized at the median) with the incidence of type 2 diabetes.

To account for potential confounders, we used multivariable-adjusted Cox proportional hazards regression models (in sample 3) to relate each of the markers (independent variables all at Exam 5; separate model for each marker) to the incidence of type 2 diabetes (dependent variable through Exam 9). We adjusted these models for age, sex, smoking status, waist circumference, hypertension status, total/HDL cholesterol ratio, triglyceride levels, lipid-lowering medication, and the Physical Activity Index. Finally, using sample 3, we performed a stepwise backward selection procedure within the Cox model, forcing in all covariates mentioned above, to evaluate which of the five markers (fasting plasma insulin, $2 \mathrm{~h}$-insulin, fasting plasma glucose, 2h-glucose, and $\mathrm{HbA}_{1 \mathrm{C}}$ ), revealed the strongest association with incident type 2 diabetes. Stepwise backward selection of the markers in the model was based on entry and exit criteria of $\mathrm{p}<0.05$.

We evaluated possible non-linear relations for insulin and glucose in relation to the incidence of diabetes by adding the respective glycemic marker as a quadratic term. Since $2 \mathrm{~h}$-insulin was indicative of a non-linear association, we performed a sensitivity analysis for the stepwise backward selection by adding the quadratic term for 2h-insulin and our results remained consistent (data not shown). 
Table 1 Baseline characteristics of study samples

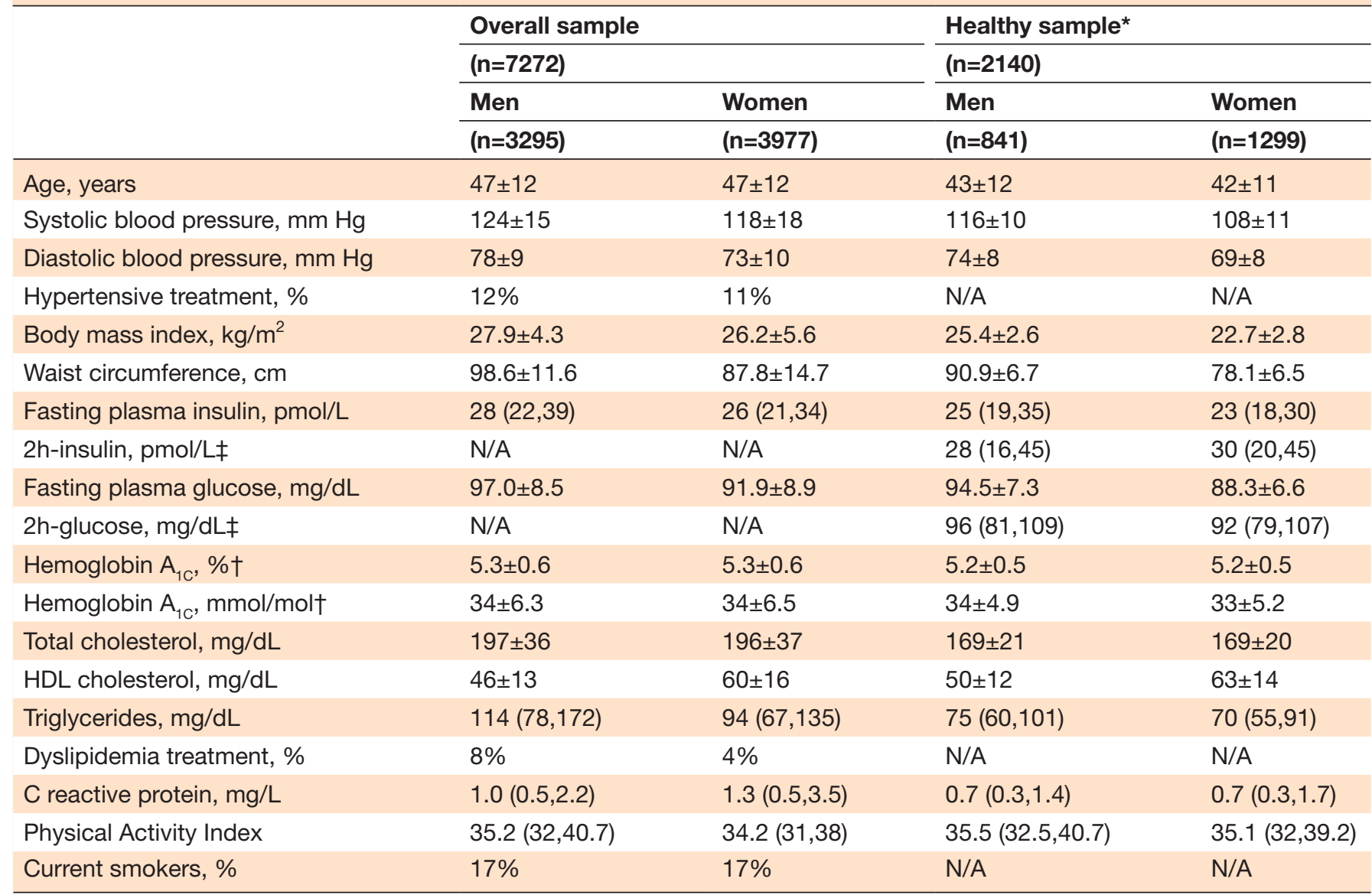

N/A indicates not available/not applicable.

*The healthy sample consists of non-smoking participants free of prevalent diabetes, cardiovascular disease, dyslipidemia, hypertension, and abdominal obesity.

†Hemoglobin $A_{1 C}$ was only available in the Offspring cohort and Gen 3, exam 2 participants.

$\ddagger 2 \mathrm{~h}$-insulin and $2 \mathrm{~h}$-glucose were only available at Offspring cohort examination cycle 5 . Continuous measures are presented as mean $\pm \mathrm{SD}$ or median (Q1, Q3).

HDL, high-density lipoprotein.

All analyses were performed with SAS V.9.4 (Cary, North Carolina, USA), and a two-sided $p$ value of $<0.05$ was considered statistically significant.

\section{RESULTS}

Baseline characteristics of the overall and the healthy subsample (consisting of non-smoking participants free of prevalent diabetes, CVD, dyslipidemia, hypertension, and abdominal obesity) are displayed in table 1. We observed the expected differences in the cardiovascular and metabolic profiles between the two samples.

\section{Cross-sectional and longitudinal correlates of fasting plasma insulin}

On multivariable adjustment, fasting plasma insulin levels were inversely associated with age, male sex (indicating higher levels in women), and the Physical Activity Index; whereas waist circumference, the total/HDL cholesterol ratio, and triglyceride levels were positively associated with fasting plasma insulin levels over the life course (table 2). When we replaced fasting plasma glucose with $\mathrm{HbA}_{1 \mathrm{C}}$, results were relatively similar, except for systolic BP which became associated, and physical activity was no longer associated with fasting plasma insulin in our longitudinal analyses (table 2). Our results remained consistent when we used non-standardized fasting plasma insulin as the outcome variable and included 'assay method' as a random effect in the model (online supplemental table 2).

In cross-sectional analyses, waist circumference, the total/ HDL cholesterol ratio, and circulating triglyceride concentrations were positively associated with fasting plasma insulin concentrations in a model that included fasting plasma glucose (Model 1; table 3). When we replaced fasting plasma glucose with $\mathrm{HbA}_{1 \mathrm{C}}$, only triglyceride levels were significantly associated with fasting plasma insulin in cross-sectional analyses (table 3). We did not observe statistically significant interactions of glycemic status (fasting plasma glucose or $\mathrm{HbA}_{1 \mathrm{C}}$ ) and sex for fasting plasma insulin ( $>0.05)$. The quadratic term for fasting plasma glucose was not statistically significantly related to fasting plasma insulin (online supplemental table 3). 
Table 2 Longitudinal correlates of fasting plasma insulin

\begin{tabular}{|c|c|c|c|c|}
\hline \multirow[b]{2}{*}{ Potential correlates } & \multicolumn{2}{|c|}{$\begin{array}{l}\text { Model } 1 \\
\text { (adjusted for fasting plasma glucose) }\end{array}$} & \multicolumn{2}{|c|}{$\begin{array}{l}\text { Model } 2 \\
\text { (adjusted for } \mathrm{HbA}_{1 \mathrm{c}} \text { ) }\end{array}$} \\
\hline & $\beta$ (SE) & $P$ value & $\beta$ (SE) & $P$ value \\
\hline Age, years & $-0.11(0.02)$ & $<0.0001$ & $-0.10(0.03)$ & 0.001 \\
\hline Male sex & $-0.48(0.06)$ & $<0.0001$ & $-0.35(0.08)$ & $<0.0001$ \\
\hline Waist circumference, $\mathrm{cm}$ & $0.24(0.03)$ & $<0.0001$ & $0.31(0.04)$ & $<0.0001$ \\
\hline Systolic blood pressure, $\mathrm{mm} \mathrm{Hg}$ & $0.02(0.02)$ & 0.39 & $0.07(0.03)$ & 0.02 \\
\hline Total/HDL cholesterol ratio, mg/dL & $0.08(0.02)$ & 0.002 & $0.11(0.03)$ & 0.004 \\
\hline Triglycerides, mg/dL & $0.18(0.02)$ & $<0.0001$ & $0.17(0.03)$ & $<0.0001$ \\
\hline $\mathrm{C}$ reactive protein, $\mathrm{mg} / \mathrm{L}$ & $0.03(0.02)$ & 0.09 & $0.03(0.03)$ & 0.28 \\
\hline Physical Activity Index & $-0.01(0.003)$ & 0.004 & $-0.002(0.004)$ & 0.53 \\
\hline Fasting plasma glucose, $\mathrm{mg} / \mathrm{dL}$ & $0.25(0.02)$ & $<0.0001$ & - & - \\
\hline $\mathrm{HbA}_{1 \mathrm{C}}, \%$ & - & - & $0.06(0.03)$ & 0.054 \\
\hline
\end{tabular}

$\beta$ indicates the regression coefficient; SE indicates standard error of $\beta$. Fasting plasma insulin was log-transformed and standardized within each exam. The beta coefficients indicate the change in standardized log-fasting plasma insulin per 1-SD increment in the continuous variables, per 1-unit increment of the Physical Activity Index, or presence versus absence of categorical variables $(n=2140)$.

Bold indicates $\mathrm{p}<0.05$.

$\mathrm{HbA}_{1 \mathrm{C}}$, Hemoglobin $\mathrm{A}_{1 \mathrm{C}} ; \mathrm{HDL}$, high-density lipoprotein.

\section{Cross-sectional correlates of $2 \mathrm{~h}$-insulin}

Male sex (inversely related), the total/HDL cholesterol ratio, and fasting insulin levels (positive relations) were significantly associated with $2 \mathrm{~h}$-insulin (table 3 ), regardless of adjusting for fasting plasma glucose or 2h-glucose. The quadratic term for 2h-glucose, but not for fasting plasma glucose, was statistically significantly related to $2 \mathrm{~h}$ plasma insulin (online supplemental table 3). However, even after adding the quadratic term for 2h-glucose, the coefficient estimates of all variables in the model remained essentially unchanged (online supplemental table 3 compared with table 3 ).

Table 3 Cross-sectional correlates of fasting and 2-hour (2h) plasma insulin

\begin{tabular}{|c|c|c|c|c|c|c|c|c|}
\hline \multirow[b]{3}{*}{ Potential correlates } & \multicolumn{4}{|c|}{ Fasting plasma insulin } & \multicolumn{4}{|c|}{ 2-hour plasma insulin } \\
\hline & \multicolumn{2}{|c|}{$\begin{array}{l}\text { Model } 1 \\
\text { (adjusted for fasting } \\
\text { plasma glucose) }\end{array}$} & \multicolumn{2}{|c|}{$\begin{array}{l}\text { Model } 2 \\
\text { (adjusted for } \mathrm{HbA}_{1 \mathrm{c}} \text { ) }\end{array}$} & \multicolumn{2}{|c|}{$\begin{array}{l}\text { Model } 1 \\
\text { (multivariable-adjusted, } \\
\text { including fasting plasma insulin } \\
\text { and fasting plasma glucose) }\end{array}$} & \multicolumn{2}{|c|}{$\begin{array}{l}\text { Model } 2 \\
\text { (multivariable-adjusted, } \\
\text { including fasting plasma } \\
\text { insulin and } 2 \text { h-glucose) }\end{array}$} \\
\hline & $\beta$ (SE) & $P$ value & $\beta$ (SE) & $P$ value & $\beta$ (SE) & $P$ value & $\beta$ (SE) & $P$ value \\
\hline Age, years & $-0.01(0.04)$ & 0.82 & $-0.02(0.05)$ & 0.72 & $0.10(0.04)$ & 0.02 & $-0.01(0.03)$ & 0.78 \\
\hline $\begin{array}{l}\text { Systolic blood pressure, } \\
\mathrm{mm} \mathrm{Hg}\end{array}$ & $0.02(0.04)$ & 0.66 & $0.02(0.05)$ & 0.78 & $0.06(0.04)$ & 0.19 & $-0.001(0.04)$ & 0.97 \\
\hline $\begin{array}{l}\text { Total/HDL cholesterol } \\
\text { ratio, } \mathrm{mg} / \mathrm{dL}\end{array}$ & $0.12(0.05)$ & 0.02 & $0.12(0.06)$ & 0.06 & $0.15(0.05)$ & 0.003 & $0.12(0.04)$ & 0.003 \\
\hline Triglycerides, mg/dL & $0.15(0.05)$ & 0.001 & $0.17(0.06)$ & 0.004 & $0.04(0.05)$ & 0.42 & $-0.02(0.04)$ & 0.62 \\
\hline $\begin{array}{l}\text { Log-fasting plasma } \\
\text { insulin, pmol/L }\end{array}$ & - & - & - & - & $0.41(0.04)$ & $<0.0001$ & $0.37(0.03)$ & $<0.0001$ \\
\hline $\mathrm{HbA}_{1 \mathrm{C}}, \%$ & - & - & $0.05(0.05)$ & 0.36 & - & - & - & - \\
\hline $2 \mathrm{~h}$-glucose, mg/dL & - & - & - & - & - & - & $0.53(0.03)$ & $<0.0001$ \\
\hline
\end{tabular}

$\beta$ indicates the regression coefficient; SE indicates standard error of $\beta$. The regression coefficients indicate the change in standardized log-fasting plasma insulin and log-2h-plasma insulin per 1-standard deviation increment in the continuous variables, per 1-unit increment of the Physical Activity Index, or presence vs absence of categorical variables $(n=565)$.

Bold indicates $\mathrm{p}<0.05$.

$\mathrm{HbA}_{1 \mathrm{C}}$, hemoglobin $\mathrm{A}_{1 \mathrm{C}} ; \mathrm{HDL}$, high-density lipoprotein. 
Table 4 Association of glycemic markers with incident type 2 diabetes (separate model for each marker)

\begin{tabular}{llll}
\hline & N events/N at risk & HR * (95\% Cl) & P value \\
\hline Fasting plasma insulin, pmol/L & $352 / 2819$ & $1.36(1.21$ to 1.52) & $<0.0001$ \\
2h-insulin, pmol/L & $344 / 2750$ & $1.33(1.23$ to 1.44) & $<0.0001$ \\
Fasting plasma glucose, $\mathrm{mg} / \mathrm{dL}$ & $350 / 2792$ & $2.76(2.46$ to 3.11$)$ & $<0.0001$ \\
2h-glucose, $\mathrm{mg} / \mathrm{dL}$ & $345 / 2755$ & $1.91(1.74$ to 2.09$)$ & $<\mathbf{0 0 0 0 1}$ \\
Hemoglobin $\mathrm{A}_{1 \mathrm{C}}, \%(\mathrm{mmol} / \mathrm{mol})$ & $254 / 2043$ & $1.27(1.16$ to 1.39$)$ & $<0.0001$ \\
\hline
\end{tabular}

Bold indicates $\mathrm{p}<0.05$.

*Models were adjusted for age, sex, current smoking, waist circumference, hypertension status, total/HDL cholesterol ratio, triglyceride levels, lipid-lowering medication, and the Physical Activity Index. Fasting plasma insulin was log-transformed. All glycemic markers were standardized (mean $=0, S D=1$ ). Thus, the HRs are given per 1-SD increment in the glycemic marker.

2h, 2-hour; HR, Hazard Ratio.

\section{Association of all insulin and glucose markers with type 2 diabetes}

The median follow-up time for the incidence of type 2 diabetes was 18 years. During the follow-up period, between 254 (for $\mathrm{HbA}_{1 \mathrm{c}}$; table 4) and 352 participants (for fasting plasma insulin) developed new-onset type 2 diabetes. All markers (fasting plasma insulin, 2h-insulin, fasting plasma glucose, 2h-glucose, $\mathrm{HbA}_{1 \mathrm{C}}$ ) were positively associated with time to type 2 diabetes (online supplemental figure 2; table 4). Using a backward stepwise selection procedure with all five glycemic markers in the same model, only fasting blood glucose and $2 \mathrm{~h}$-glucose levels remained significantly associated with type 2 diabetes (online supplemental table 4).

\section{CONCLUSIONS}

Using multiple observations from two generations of the FHS, we assessed longitudinal and cross-sectional correlates of fasting plasma insulin levels and crosssectional correlates of $2 \mathrm{~h}$-insulin levels in relatively healthy study participants (eg, non-smoking individuals, free of diabetes, CVD, dyslipidemia, hypertension, and abdominal obesity). We also analyzed the association of a broad spectrum of glycemic markers (fasting plasma insulin, 2h-insulin, fasting plasma glucose, 2h-glucose, and $\mathrm{HbA}_{1 \mathrm{C}}$ ) with incident type 2 diabetes over a median follow-up of 18 years.

\section{Principal findings}

First, we identified common correlates of fasting and 2h-insulin levels. Specifically, we observed that lipid traits (triglyceride levels and/or the total/HDL cholesterol ratio) and sex (higher values in women) were significantly associated with both fasting (longitudinally and/or cross-sectionally) and 2h-insulin levels. Second, age and physical activity (both inverse), and waist circumference (positive) were significant correlates of the fasting plasma insulin, but not $2 \mathrm{~h}$-insulin after adjusting for $2 \mathrm{~h}$-glucose. Third, fasting and 2h-glucose levels displayed the strongest associations (of all glycemic markers evaluated) with the risk for incident type 2 diabetes.

\section{Comparison with the literature}

Distinct correlates of fasting and $2 \mathrm{~h}$-insulin concentrations

Over the life course, age, physical activity, and waist circumference were associated with fasting insulin concentrations, but these traits were not associated with 2h-insulin in cross-sectional analyses that adjusted for 2h-glucose. These differences are interesting because fasting and postprandial glucose and insulin levels reflect different physiological processes and have distinct metabolic implications. ${ }^{14}$ As an example, $2 \mathrm{~h}$-insulin concentrations reflect in part the pancreatic response to a glucose challenge; the lack of association of $2 \mathrm{~h}$-insulin with age and physical activity may suggest that this response does not seem to change with age and is not impacted substantially by physical activity.

Fasting insulin is in part determined by baseline insulin production and by insulin sensitivity vs insulin resistance in the periphery. It is conceivable that the physiological actions of insulin, for example, in the peripheral muscles, are improved by regular physical activity, which would explain the association of fasting insulin with physical activity, particularly in our longitudinal analyses over the life course.

The association of fasting insulin with waist circumference is consistent with the notion that abdominal obesity is an essential correlate of insulin resistance and hyperinsulinemia. ${ }^{20}$ Overall, our observations suggest that lifestyle measures, such as physical activity, may have a more profound effect on baseline (fasting) rather than postprandial (2h) insulin levels, and particularly over more extended periods; this premise warrants further investigation.

\section{Common correlates of fasting and $2 \mathrm{~h}$-insulin concentrations}

In our healthy community-based sample, the total/HDL cholesterol ratio and/or triglyceride levels were positively associated with 2h-insulin (cross-sectional) and fasting insulin concentrations in cross-sectional and longitudinal analyses. Similar positive associations of fasting plasma insulin with triglyceride levels and inverse associations with HDL cholesterol were also reported in children and young adults in prior studies. ${ }^{721}$ This constellation resembles the lipid abnormalities frequently observed in type 2 diabetes and in the metabolic syndrome, commonly 
referred to as 'diabetic dyslipidemia': high triglyceride levels, low HDL levels and high low-density lipoprotein (LDL) cholesterol levels. The pathophysiology of this condition has been comprehensively reviewed elsewhere. ${ }^{22}$ Indeed, insulin resistance and insulin seem to play a pivotal role in developing these lipid alterations. ${ }^{22}$ Insulin promotes lipogenesis (triglyceride synthesis) and inhibits lipolysis in adipocytes, ${ }^{20} 23$ and affects the activity of different enzymes involved in lipid and lipoprotein metabolism, including the hormone-sensitive lipase and lipoprotein lipase. ${ }^{20}{ }^{24}$ The fact that we observed consistent associations of these lipid traits with fasting and 2h-insulin levels in our sample highlights the significance of insulin not only for glucose hemostasis but also for lipid and lipoprotein metabolism in healthy individuals. ${ }^{23}$

On a similar note, men had lower levels of fasting insulin over the life course and lower 2h-insulin levels than women. Differences between women and men with regard to fasting and post glucose challenge insulin and glucose levels have been reported in prior studies; ${ }^{25}{ }^{26}$ and a recent genomewide analysis reported sex differences in their association with fasting insulin levels for defined genetic variants. ${ }^{25}$

\section{Association of glycemic markers with incident type 2 diabetes}

Glycemic markers such as fasting glucose,${ }^{27}$ 2h-glucose ${ }^{28}$ and $\mathrm{HbA}_{1 \mathrm{C}}{ }^{29}$ and different insulin measures (including concentrations of insulin and proinsulin), ${ }^{30}$ have been related to the incidence of diabetes. Investigators have also evaluated whether a combination of these markers improved the prediction of type 2 diabetes. ${ }^{27}{ }^{28} \mathrm{In}$ most scenarios, higher or above-threshold levels of two or more such markers conferred higher risks for incident type 2 diabetes as compared with individuals who had elevated levels on only one marker. ${ }^{2728}$ Consistent with these observations, all five markers evaluated in our sample (fasting plasma insulin, 2h-insulin, fasting plasma glucose, 2h-glucose, $\mathrm{HbA}_{1 \mathrm{C}}$ ) were significantly associated with incident type 2 diabetes in multivariable-adjusted models (separate models for each glycemic marker). However, using a backward selection procedure with all glycemic markers in the model, only fasting blood glucose and 2h-glucose levels remained significantly associated with incident type 2 diabetes. Thus, among all glycemic and insulin traits, both glucose measures displayed the strongest associations with new-onset type 2 diabetes. The clinical diagnosis of type 2 diabetes is based on blood glucose levels or glycosylation of $\mathrm{HbA}_{1 \mathrm{C}}$ and is not based on insulin levels; this could, in part, explain the stronger association of glucose traits (as compared with insulin traits) with incident type 2 diabetes.

\section{Strengths and limitations}

Strengths of our investigation include the large sample size, the community-based design including crosssectional and longitudinal components, the comprehensive phenotyping of our sample with respect to potential correlates and confounders and the availability of repeated measurements of fasting plasma insulin over
21 years. Moreover, the availability of other glycemic markers (including 2h-insulin, fasting plasma glucose, 2h-glucose, and $\mathrm{HbA}_{1 \mathrm{C}}$ ) allowed us to compare comprehensively and conjointly model all glycemic markers in relation to incident type 2 diabetes. Compared with other longitudinal studies with repeated insulin measurements, ${ }^{10-12}$ our sample covered a broader age range (19-83 years), included slightly more women than men, and focused on relatively healthy non-smoking individuals free of prevalent diabetes, CVD, dyslipidemia, hypertension, and abdominal obesity, allowing analyses unconfounded by these conditions.

The following limitations of our study merit consideration. Insulin was measured using different assays across examination cycles. To account for the variability introduced by different assays, we standardized insulin levels within each exam. An additional limitation is that $2 \mathrm{~h}$-insulin levels were available only at examination cycle 5 of the Offspring cohort. We might have underestimated the incidence of type 2 diabetes since ascertainment of incident diabetes did not include the use of $\mathrm{HbA}_{1 \mathrm{C}}$ and of postload glucose. Finally, our analyses were conducted in white individuals of European ancestry, focusing on healthy individuals (as defined above).

Therefore, our findings cannot be generalized to other ethnicities. It is noteworthy that the relative contributions of adiposity, insulin resistance and B-cell function to the risk of diabetes may be different between Europeans and East Asians. ${ }^{31}$ East Asians, for example, tend to be less obese but more insulin resistant as compared with Europeans. ${ }^{31} 32$ Therefore, follow-up studies in East Asians and other ethnicities are warranted, and the comparison of these studies with our data may be critical.

\section{CONCLUSION}

Fasting and 2h-insulin levels share common but also have distinct clinical correlates. The consistent associations of lipid traits with fasting and $2 \mathrm{~h}$-insulin levels underscore the relevance of insulin levels not only for glucose homeostasis but also for lipid and lipoprotein metabolism. Furthermore, insulin levels (and other glycemic markers such as fasting glucose, $2 \mathrm{~h}$-glucose, and $\mathrm{HbA}_{1 \mathrm{C}}$ ) may be markers of future diabetes risk.

\section{Author affiliations}

${ }^{1}$ The Framingham Heart Study, Framingham, Massachusetts, USA

${ }^{2}$ Institute for Epidemiology, Kiel University, Kiel, Germany

${ }^{3}$ Section of of Preventive Medicine and Epidemiology, Department of Medicine,

Boston University School of Medicine, Boston, Massachusetts, USA

${ }^{4}$ Department of Biostatistics, Boston University, School of Public Health, Boston, Massachusetts, USA

${ }^{5}$ Department of Medicine, Division of Endocrinology, Diabetes \& Metabolism, Johns Hopkins University School of Medicine, Baltimore, Maryland, USA

${ }^{6}$ Department of Epidemiology, Boston University, School of Public Health, Boston, Massachusetts, USA

${ }^{7}$ Boston University Center for Computing and Data Sciences, Boston,

Massachusetts, USA

Contributors Conception and design: RSV, VX; Data analysis and interpretation: SP, VX, WL, CMO, RSV, JBE; Manuscript drafting: WL, VX, CM0, RSV; Critical 
revision of the manuscript for important intellectual content: all; Final approval of the manuscript: all. VX is the guarantor of this work and, as such, accepts full responsibility for the finished work, had access to the data, and controlled the decision to publish.

Funding This work was supported by the National Heart, Lung and Blood Institute's Framingham Heart Study (Contracts No. N01-HC-25195, HHSN268201500001I and 75N92019D00031; to RSV), and the following grants: T32 HL125232 (JBE), R01HL093328 (RSV), R01HL107385 (RSV).

Competing interests None declared.

Patient consent for publication Not applicable.

Ethics approval This study involves human participants and all study protocols for the FHS Offspring and Gen 3 cohorts were approved by the Boston Medical Center and Boston University Medical Campus Institutional Review Board (Protocol Number: H-32132). Participants gave informed consent to participate in the study before taking part.

Provenance and peer review Not commissioned; externally peer reviewed.

Data availability statement Data are available upon reasonable request. The data that support the observations reported in the present manuscript are available from the corresponding author $(\mathrm{VX})$ upon reasonable request.

Supplemental material This content has been supplied by the author(s). It has not been vetted by BMJ Publishing Group Limited (BMJ) and may not have been peer-reviewed. Any opinions or recommendations discussed are solely those of the author(s) and are not endorsed by BMJ. BMJ disclaims all liability and responsibility arising from any reliance placed on the content. Where the content includes any translated material, BMJ does not warrant the accuracy and reliability of the translations (including but not limited to local regulations, clinical guidelines, terminology, drug names and drug dosages), and is not responsible for any error and/or omissions arising from translation and adaptation or otherwise.

Open access This is an open access article distributed in accordance with the Creative Commons Attribution Non Commercial (CC BY-NC 4.0) license, which permits others to distribute, remix, adapt, build upon this work non-commercially, and license their derivative works on different terms, provided the original work is properly cited, appropriate credit is given, any changes made indicated, and the use is non-commercial. See: http://creativecommons.org/licenses/by-nc/4.0/.

ORCID iDs

Wolfgang Lieb http://orcid.org/0000-0003-2544-4460

Camila Maciel de Oliveira http://orcid.org/0000-0001-6823-7395

Justin Basile Echouffo-Tcheugui http://orcid.org/0000-0002-8460-1617

Ramachandran S Vasan http://orcid.org/0000-0001-7357-5970

Vanessa Xanthakis http://orcid.org/0000-0002-7352-621X

\section{REFERENCES}

1 Wilcox G. Insulin and insulin resistance. Clin Biochem Rev 2005;26:19-39.

2 Tokarz VL, MacDonald PE, Klip A. The cell biology of systemic insulin function. J Cell Biol 2018;217:2273-89.

3 Wang L, Li X, Wang Z, et al. Trends in prevalence of diabetes and control of risk factors in diabetes among US adults, 1999-2018. JAMA 2021;326:704.

4 Zavaroni I, Bonini L, Gasparini P, et al. Hyperinsulinemia in a normal population as a predictor of non-insulin-dependent diabetes mellitus, hypertension, and coronary heart disease: the Barilla factory revisited. Metabolism 1999;48:989-94.

5 Pyörälä M, Miettinen $\mathrm{H}$, Halonen $\mathrm{P}$, et al. Insulin resistance syndrome predicts the risk of coronary heart disease and stroke in healthy middle-aged men: the 22-year follow-up results of the Helsinki Policemen study. Arterioscler Thromb Vasc Biol 2000;20:538-44.

6 Fu Z, Gilbert ER, Liu D. Regulation of insulin synthesis and secretion and pancreatic beta-cell dysfunction in diabetes. Curr Diabetes Rev 2013;9:25-53

7 Manolio TA, Savage PJ, Burke GL, et al. Association of fasting insulin with blood pressure and lipids in young adults. The cardia study. Arteriosclerosis 1990;10:430-6.

8 Manolio TA, Savage PJ, Burke GL, et al. Correlates of fasting insulin levels in young adults: the cardia study. J Clin Epidemiol 1991;44:571-8.

9 Burchfiel CM, Curb JD, Sharp DS, et al. Distribution and correlates of insulin in elderly men. The Honolulu heart program. Arterioscler Thromb Vasc Biol 1995;15:2213-21.
10 Tabák AG, Jokela M, Akbaraly TN, et al. Trajectories of glycaemia, insulin sensitivity, and insulin secretion before diagnosis of type 2 diabetes: an analysis from the Whitehall II study. Lancet 2009;373:2215-21.

11 Ohn JH, Kwak SH, Cho YM, et al. 10-Year trajectory of $\beta$-cell function and insulin sensitivity in the development of type 2 diabetes: a community-based prospective cohort study. Lancet Diabetes Endocrinol 2016;4:27-34.

12 Herder C, Færch K, Carstensen-Kirberg M, et al. Biomarkers of subclinical inflammation and increases in glycaemia, insulin resistance and beta-cell function in non-diabetic individuals: the Whitehall II study. Eur J Endocrinol 2016;175:367-77.

13 Hulman A, Simmons RK, Brunner EJ, et al. Trajectories of glycaemia, insulin sensitivity and insulin secretion in South Asian and white individuals before diagnosis of type 2 diabetes: a longitudinal analysis from the Whitehall II cohort study. Diabetologia 2017;60:1252-60.

14 Abdul-Ghani MA, Tripathy D, DeFronzo RA. Contributions of beta-cell dysfunction and insulin resistance to the pathogenesis of impaired glucose tolerance and impaired fasting glucose. Diabetes Care 2006;29:1130-9.

15 Splansky GL, Corey D, Yang Q, et al. The third generation cohort of the National heart, lung, and blood Institute's Framingham heart study: design, recruitment, and initial examination. Am J Epidemiol 2007; 165:1328-35

16 The DCCT Research Group. Feasibility of centralized measurements of glycated hemoglobin in the diabetes control and complications trial: a multicenter study. The DCCT Research Group. Clin Chem 1987;33:2267-71.

17 Tan ZS, Spartano NL, Beiser AS, et al. Physical activity, brain volume, and dementia risk: the Framingham study. J Gerontol A Biol Sci Med Sci 2017;72:789-95.

18 American Diabetes Association. 2. Classification and Diagnosis of Diabetes: Standards of Medical Care in Diabetes-2021. Diabetes Care 2021;44:S15-33.

19 Klein S, Allison DB, Heymsfield SB, et al. Waist circumference and cardiometabolic risk: a consensus statement from shaping America's health: association for weight management and obesity prevention; NAASO, the obesity Society; the American Society for nutrition; and the American diabetes association. Diabetes Care 2007;30:1647-52.

20 Kahn BB, Flier JS. Obesity and insulin resistance. J Clin Invest 2000;106:473-81.

21 Jiang X, Srinivasan SR, Webber LS, et al. Association of fasting insulin level with serum lipid and lipoprotein levels in children, adolescents, and young adults: the Bogalusa heart study. Arch Intern Med 1995;155:190-6.

22 Mooradian AD. Dyslipidemia in type 2 diabetes mellitus. Nat Clin Pract Endocrinol Metab 2009;5:150-9.

23 Saltiel AR, Kahn CR. Insulin signalling and the regulation of glucose and lipid metabolism. Nature 2001;414:799-806.

24 Meijssen S, Cabezas MC, Ballieux CG, et al. Insulin mediated inhibition of hormone sensitive lipase activity in vivo in relation to endogenous catecholamines in healthy subjects. J Clin Endocrinol Metab 2001:86:4193-7.

25 Lagou V, Mägi R, Hottenga J-J, et al. Sex-dimorphic genetic effects and novel loci for fasting glucose and insulin variability. Nat Commun 2021;12:24

26 Morris A. Sex differences for fasting levels of glucose and insulin: expanding our understanding. Nat Rev Endocrinol 2021:17:131.

27 Heianza Y, Hara S, Arase Y, et al. HbA1c 5.7-6.4\% and impaired fasting plasma glucose for diagnosis of prediabetes and risk of progression to diabetes in Japan (TOPICS 3): a longitudinal cohort study. Lancet 2011;378:147-55.

$28 \mathrm{Lu} \mathrm{J}$, He J, Li M, et al. Predictive Value of Fasting Glucose, Postload Glucose, and Hemoglobin $\mathrm{A}_{1 \mathrm{c}}$ on Risk of Diabetes and Complications in Chinese Adults. Diabetes Care 2019;42:1539-48.

29 Zhang X, Gregg EW, Williamson DF, et al. A1C level and future risk of diabetes: a systematic review. Diabetes Care 2010;33:1665-73.

30 Hanley AJG, D'Agostino R, Wagenknecht LE, et al. Increased proinsulin levels and decreased acute insulin response independently predict the incidence of type 2 diabetes in the insulin resistance atherosclerosis study. Diabetes 2002;51:1263-70.

31 Ma RCW, Chan JCN. Type 2 diabetes in East Asians: similarities and differences with populations in Europe and the United States. Ann N Y Acad Sci 2013;1281:64-91.

32 Chiu KC, Cohan P, Lee NP, et al. Insulin sensitivity differs among ethnic groups with a compensatory response in beta-cell function. Diabetes Care 2000;23:1353-8. 